\title{
Two pedigrees with restless legs syndrome in Brazil
}

\author{
A.M. Esteves ${ }^{1,2}$, M. Pedrazzoli ${ }^{1}$, M. Bagnato ${ }^{1}$, F. Moreira1, M.T. de Mello ${ }^{1,2}$ and \\ S. Tufik ${ }^{1,2}$ \\ ${ }^{1}$ Departamento de Psicobiologia, ${ }^{2}$ Centro de Estudos em Psicobiologia e Exercício, Escola Paulista de \\ Medicina, Universidade Federal de São Paulo, São Paulo, SP, Brasil \\ Correspondence to: M. Pedrazzoli, Departamento de Psicobiologia, EPM, UNIFESP, Rua Napoleão de \\ Barros 925, $3^{\circ}$ andar, 04024-002 São Paulo, SP, Brasil \\ Fax: +55-11-5572-0177. E-mail: pedrazzo@psicobio.epm.br
}

\begin{abstract}
Numerous studies have suggested a substantial genetic contribution in the etiology of the primary form of restless legs syndrome (RLS) and periodic leg movements (PLM). We describe the symptoms, the sleep profiles and physiological parameters of two families in which several members present RLS/PLM. The proband of family 1 is a 70-year-old woman and the proband of family 2 is a 57-year-old woman; both have exhibited the symptoms since the age of 20 years. All patients in both families were diagnosed with RLS according to the criteria of the International RLS Study Group. Polysomnographic recordings were performed to quantify and to describe PLM during sleep. Sleep parameters showed decreased sleep efficiency, increased sleep latency in the arousal index and the presence of PLM in all subjects. One of the families showed an exact profile of dominant inheritance with anticipation of age at onset. In the other family, the founders were blood relatives and there was no affected member in the third generation suggesting a recessive mode of inheritance. RLS/PLM is a prevalent sleep disorder affecting about 5 to $15 \%$ of the population and one that substantially impairs healthy sleep patterns. Efforts to understand the underlying pathophysiology will contribute to improve the sleep and life quality of these patients.
\end{abstract}

Key words: Restless legs syndrome; Periodic leg movements; Genetics; Sleep

Research supported by grants from Associação Fundo de Incentivo à Psicofarmacologia (AFIP), FAPESP (No. 03/06297-3 and CEPID 98/143033), FADA and CNPq.

Received June 15, 2007. Accepted December 10, 2007

\section{Introduction}

Restless legs syndrome (RLS) is a common disorder affecting 2 to $5 \%$ of the general population. The four cardinal diagnostic features of RLS include: 1) an urge to move the limbs that is usually associated with paresthesias or dysesthesias, 2) symptoms that start or become worse with rest, 3) at least partial relief of symptoms with physical activity, and 4) worsening of symptoms in the evening or at night (1).

In $85 \%$ of patients, RLS is associated with periodic leg movements (PLM) during sleep, which occur mostly during stage II sleep. PLM occur every 20-40 s, and sleep disruption results in daytime fatigue. The pathophysiology of the syndrome has not been elucidated fully but may involve dopaminergic dysfunction and abnormalities in metabolism of iron within the brain (2).

Numerous studies have suggested a substantial genetic contribution to the etiology of the primary form of RLS. Familial aggregation has been reported since its original clinical description, and up to $40 \%$ of sporadic cases show a positive family history (3).

RLS usually begins in the second decade of life and often follows an intermittent, fluctuating course. At the onset of the disorder, the diagnosis is sometimes not obvious because symptoms are generally mild, and symptom-free periods can occur. Treatment is usually initiated in the fifth decade of life, although some patients with familial RLS seek treatment early in their youth. The genetic basis of RLS is still unknown, and there is no specific 
test to diagnose RLS or to specify and limit the clinical picture (4). A genetic marker on chromosome $6 \mathrm{p} 21.2$ that is associated with susceptibility to PLM during sleep has been reported recently (5).

Several studies have investigated the occurrence of familial RLS in different patient populations (6). However, only a limited number of studies have focused on relatives through personal interviews of the index cases to verify the diagnosis and occurrence of familial cases.

We herein describe the symptoms and sleep and physiological parameters of two Brazilian families in which several members present RLS.

\section{Subjects and Methods}

\section{Casuistic}

We investigated two Brazilian families showing a familial history of RLS. The proband of family 1 is a 70 -year-old woman with no clear ascendancy although she reported all-Brazilian ancestors. All members of her family present clear brown skin color as seen in mulattos. The proband of family 2 is a 57 -year-old Caucasian woman with German ascendancy. Both women were treated in the Sleep Insti-

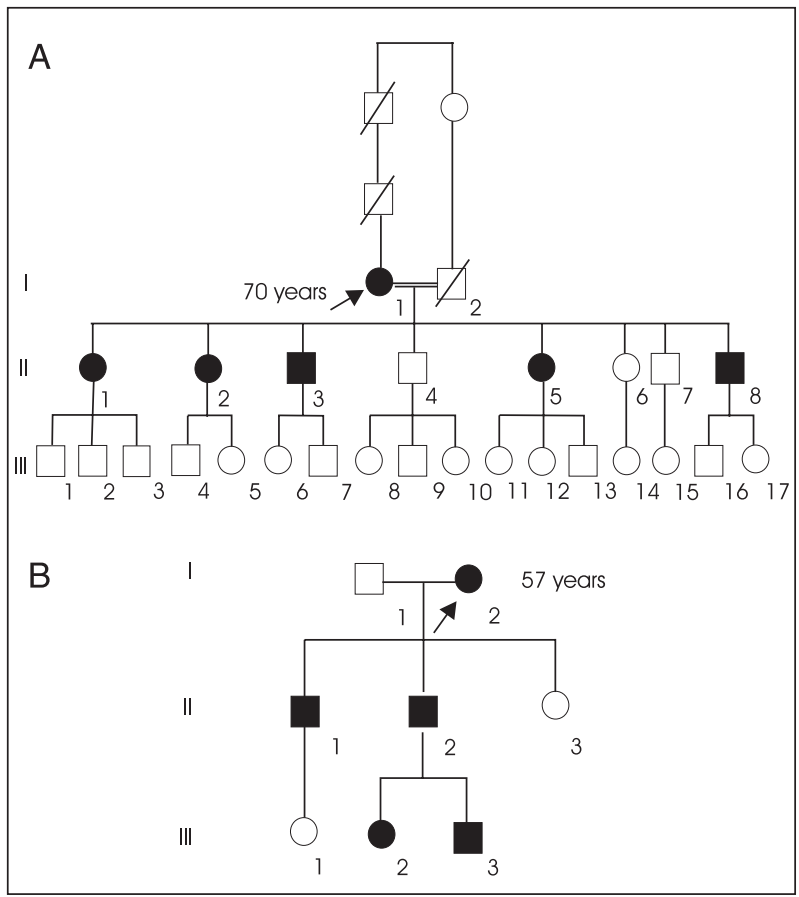

Figure 1. $A$, Family 1 pedigree, black color figures represent the affected members. The arrow indicates the proband, who is blood relative of her husband. $B$, Family 2 pedigree, black color figures represent the affected members. The arrow indicates the proband. tute of São Paulo. Pedigrees of family 1 and family 2 are shown in Figure 1.

The research design was approved by the Institutional Ethics Committee (Ref. No. 481/01) of the Universidade Federal de São Paulo. Participants signed consent forms authorizing collection of data.

\section{Diagnosis}

The primary analyses were based on identification of subjects, probands and family members, and self-reports of RLS and PLM. Subsequently, all patients truly diagnosed with RLS according to the criteria of the International RLS Study Group were examined using a standard questionnaire that included demographic data, family history, clinical symptoms, subjective sleep disturbances, and course of the disorder.

Nocturnal polysomnographic recordings were performed to quantify and describe PLM during sleep in both probands and in some members of each proband's family. Clinical chemistry analysis included measurement of blood iron, ferritin, and transferrin concentrations.

\section{Examinations}

Polysomnography. The polysomnographic exam was performed in accordance with the standardized rules for sleep stages of Rechtschaffen and Kales (7) and the rules for placing electrodes of Jasper (8). Data were acquired from four electroencephalograms, two electrooculograms, and three electromyogram channels (one submandibular and two for the legs). Electrodes for PLM analysis were placed on the surface of the tibialis anterior muscle of both legs.

Polysomnographic measures of sleep continuity and sleep architecture included: total sleep time, sleep onset latency, wake after sleep onset, and sleep efficiency. Sleep architecture measures were: 1) percentages of stages 1 , 2,3 , and 4 , and rapid eye movement sleep. The PLM definition criterion was as indicated by the American Sleep Disorders Academy (1). Only PLM that occurred during non-rapid eye movement sleep was recorded.

\section{Clinical chemistry tests}

Iron, ferritin, and transferrin concentrations. The blood samples were collected into dry tubes (Vacutainer), from the forearm by vein puncture. The tubes were subsequently centrifuged (3400 rpm/10 min) at ambient temperature $\left(22^{\circ} \mathrm{C}\right)$ to serum separation. Iron concentration was measured using the VITROS Fe slide method (VITROS 750, Johnson \& Johnson, Rochester, USA) and the VITROS Chemistry Products Calibrator 4 Kit (VITROS Chemical Systems, Rochester, USA). Ferritin concentration was 
Table 1. Sleep parameters of six subjects from the two restless legs syndrome families including the probands.

\begin{tabular}{lccccccccccc}
\hline Subjects & $\begin{array}{c}\mathrm{RT} \\
(\mathrm{min})\end{array}$ & $\begin{array}{c}\mathrm{TST} \\
(\mathrm{min})\end{array}$ & $\begin{array}{c}\mathrm{SE} \\
(\%)\end{array}$ & $\begin{array}{c}\mathrm{SL} \\
(\mathrm{min})\end{array}$ & $\begin{array}{c}\text { WASO } \\
(\mathrm{min})\end{array}$ & $\begin{array}{c}\mathrm{Al} \\
(\mathrm{per} \mathrm{h})\end{array}$ & $\begin{array}{c}\mathrm{S} 1 \\
(\%)\end{array}$ & $\begin{array}{c}\mathrm{S} 2 \\
(\%)\end{array}$ & $\begin{array}{c}\text { S3/S4 } \\
(\%)\end{array}$ & $\begin{array}{c}\text { REM } \\
(\%)\end{array}$ & $\begin{array}{c}\text { PLM } \\
(\text { per h) }\end{array}$ \\
\hline $1^{*}$ & 235 & 13 & 5.5 & 89 & 96 & 69.2 & 26.9 & 65.4 & 7.7 & 0 & 71.42 \\
$2^{*}$ & 434 & 324 & 74.7 & 15 & 110 & 11.1 & 4.5 & 33 & 13.4 & 29.2 & 12 \\
$4^{\#}$ & 492 & 285 & 57.9 & 72 & 119 & 19.6 & 12.5 & 69.1 & 0 & 18.2 & 60.63 \\
$5^{\#}$ & 538 & 349 & 65 & 30.5 & 140.5 & 31.8 & 6.4 & 63.1 & 7.8 & 22.7 & 51.03 \\
$6^{\#}$ & 459 & 405 & 88.3 & 13.5 & 38.5 & 3.7 & 2.1 & 59.3 & 14.4 & 24.2 & 16.74 \\
$7^{\#}$ & 405 & 356 & 87.9 & 4 & 41 & 9.6 & 4.8 & 57.6 & 15.2 & 22.3 & 26.0 \\
Reference values & - & - & $>85$ & 30 & 30 & $<10$ & $2-5$ & $45-55$ & $13-23$ & $20-25$ & $<5$ \\
\hline
\end{tabular}

$\mathrm{RT}$ = recording time; TST = total sleep time; $\mathrm{SE}$ = sleep efficiency; $\mathrm{SL}=$ sleep latency; $\mathrm{WASO}=$ wake arousal sleep onset; $\mathrm{Al}=$ arousal index; S1, S2, S3/S4 = sleep stages 1 to $4 ; \mathrm{REM}=$ rapid eye movement sleep; PLM = periodic leg movements. "Family 1 ; *family 2.

Table 2. Plasma concentrations of iron, ferritin, and transferrin of seven subjects in families 1 and 2 including the probands.

\begin{tabular}{lccc}
\hline $\begin{array}{l}\text { Subjects } \\
\text { (gender) }\end{array}$ & $\begin{array}{c}\text { Iron } \\
(\mathrm{mg} / \mathrm{dL})\end{array}$ & $\begin{array}{c}\text { Ferritin } \\
(\mathrm{ng} / \mathrm{mL})\end{array}$ & $\begin{array}{c}\text { Transferrin } \\
(\mathrm{mg} / \mathrm{dL})\end{array}$ \\
\hline $1^{*}(\mathrm{~F})$ & 117 & 139 & 263 \\
$2^{*}(\mathrm{M})$ & 144 & 39 & 200 \\
$3^{*}(\mathrm{~F})$ & 72 & 3 & 272 \\
$4^{\#}(\mathrm{~F})$ & 71 & 238 & 239 \\
$5^{\#}(\mathrm{~F})$ & 23 & 4.4 & 279 \\
$6^{\#}(\mathrm{~F})$ & 67 & 38.6 & 262 \\
$7^{\#}(\mathrm{M})$ & 95 & 342 & 243 \\
Normal range & $50-160$ & Men 20-320 & $212-360$ \\
& \multicolumn{3}{c}{ Women 10-290 } \\
\hline
\end{tabular}

\#Family 1; *family 2.

measured using an immunoassay-type two-stage sandwich method using direct chemiluminometric detection technology and constant amounts of two anti-ferritin antibodies (Advia Centaur, Bayer, Tarrytown, USA). Transferrin concentration was measured by an antigen-antibody reaction through endpoint methods (Advia 1650, Bayer).

\section{Results}

Sleep parameters showed decreased sleep efficiency and increased sleep latency, arousal index, and the presence of PLM in all subjects evaluated in the sleep laboratory. We observed no other sleep disorders except for patient 4 (family 1), who presented a mild apnea. The family 2 proband had a sleep efficiency of only $5.5 \%$ (13 min) and no REM sleep at all, and her PLM index was very high (Table 1). The concentrations of iron, ferritin, and transferrin are shown in Table 2. Only one subject (subject 5) from family 1 had abnormal iron and ferritin concentrations.

\section{Discussion}

Herein, we report for the first time on the RLS/PLM pedigrees in Brazil. Clinical and polysomnographic evaluations in the probands and in some of the affected family members were performed to confirm the presence of the disorder.

The polysomnographic recordings show increased sleep onset latency, caused by a crawling sensation in the legs (RLS), and increased arousal and poor sleep efficiency, caused by leg movements during the night, compared with normal values described by Carskadon and Dement (9).

One possible cause of RLS is abnormalities in the metabolism of iron (2). The concentrations of iron, ferritin, and transferrin were normal in these subjects except for one subject in family 1 , who had low concentrations of iron and ferritin. Thus, it is unlikely that abnormalities in iron metabolism contributed to the disorder in these families.

The phenotype of RLS, including the symptoms and clinical signs, is similar in hereditary and nonhereditary cases. It is difficult to differentiate genetic and sporadic cases. The main difference between these two forms of the disorder is the early onset and frequent worsening of the symptoms during pregnancy in the genetic cases (10).

Investigations of single families with RLS have suggested that an autosomal dominant mode of inheritance is associated with early onset of the disorder $(11,12)$. Walters et al. (3) subdivided 105 patients according to the age at onset ( $\leq 20$ years and $\geq 20$ years). In the younger group, $81 \%$ reported a positive family history, whereas in the older group, only $58 \%$ were aware of affected family members.

Allen and Early (13) compared the effects of current age and serum ferritin concentration on RLS severity in individuals with early- and late-onset RLS. They assigned patients according to age at onset ( $\leq 45$ years and $>45$ 
years). They found an age effect in the early-onset form of RLS, which worsened gradually with age and had a limited nonsignificant relationship with serum iron concentration. In contrast, late-onset RLS occurred less commonly in families, worsened rapidly with age, and had a stronger significant relationship with iron status. These results suggest that the RLS phenotype may depend on age at onset of symptoms (13).

In our study, family 2 had the exact profile of dominant inheritance with anticipation of age at onset, as described elsewhere (12). Although it is a small pedigree, we observed RLS symptoms in each generation with anticipatory onset from the proband, who informed us that her symptoms had begun at around the age of 20 years, whereas the symptoms had started at age 5 years or younger in her grandchildren.

The pattern of inheritance seemed to be different in family 1 because there was no onset anticipation from generation to generation. The proband was married to her cousin, and we observed no anticipatory onset in the following generations or even symptoms in the third generation, which strengthens the argument of the recessive mode of inheritance. The lack of symptoms in the third generation may be explained either by a recessive mode of inheritance or their young age (under 20 years) because family members with the disorder reported symptom onset at more than 20 years of age. Whether the third generation will present RLS/PLM remains to be verified.

Genetic linkage studies have localized five different loci on chromosomes 12q, 14q, 9p, 2q, and 20p (6,14-17), and a recent study localized a marker on chromosome $6 p 21.2$ (5). The discovery of RLS genes may have a significant therapeutic impact by helping us understand the molecular mechanisms related to the different endophenotypes of RLS, which may lead to new treatments.

\section{References}

1. Anonymous. Recording and scoring leg movements. The Atlas Task Force. Sleep 1993; 16: 748-759.

2. Allen RP, Earley CJ. Restless legs syndrome: a review of clinical and pathophysiologic features. J Clin Neurophysiol 2001; 18: 128-147.

3. Walters AS, Hickey K, Maltzman J, Verrico T, Joseph D, Hening W, et al. A questionnaire study of 138 patients with restless legs syndrome: the "Night-Walkers" survey. Neurology 1996; 46: 92-95.

4. Montplaisir J, Boucher S, Poirier G, Lavigne G, Lapierre O, Lesperance $P$. Clinical, polysomnographic, and genetic characteristics of restless legs syndrome: a study of 133 patients diagnosed with new standard criteria. Mov Disord 1997; 12: 61-65.

5. Stefansson $H$, Rye DB, Hicks $A$, Petursson $H$, Ingason $A$, Thorgeirsson TE, et al. A genetic risk factor for periodic limb movements in sleep. N Engl J Med 2007; 357: 639-647.

6. Desautels A, Turecki G, Montplaisir J, Sequeira A, Verner A, Rouleau GA. Identification of a major susceptibility locus for restless legs syndrome on chromosome 12q. Am J Hum Genet 2001; 69: 1266-1270.

7. Rechtschaffen A, Kales A. Manual of standardized terminology, techniques, and scoring system for sleep stages of human subjects. Los Angeles: Brain Information Service/ Brain Research Institute, UCLA; 1968.

8. Jasper HH. The ten-twenty electrode system of the International Federation. Electroencephalogr Clin Neurophysiol 1958; 10: 371-375.

9. Carskadon MA, Dement WC. Normal human sleep: an overview. In: Kriger MH, Roth T, Dement WC (Editors), Principles and practice of sleep medicine. 2nd edn. Philadelphia: WB Saunders Company; 1994. p 16-25.
10. Winkelmann J, Wetter TC, Collado-Seidel V, Gasser T, Dichgans M, Yassouridis A, et al. Clinical characteristics and frequency of the hereditary restless legs syndrome in a population of 300 patients. Sleep 2000; 23: 597-602.

11. Lazzarini A, Walters AS, Hickey K, Coccagna G, Lugaresi E, Ehrenberg BL, et al. Studies of penetrance and anticipation in five autosomal-dominant restless legs syndrome pedigrees. Mov Disord 1999; 14: 111-116.

12. Winkelmann J, Muller-Myhsok B, Wittchen HU, Hock B, Prager $\mathrm{M}$, Pfister $\mathrm{H}$, et al. Complex segregation analysis of restless legs syndrome provides evidence for an autosomal dominant mode of inheritance in early age at onset families. Ann Neurol 2002; 52: 297-302.

13. Allen RP, Earley CJ. Defining the phenotype of the restless legs syndrome (RLS) using age-of-symptom-onset. Sleep Med 2000; 1: 11-19.

14. Bonati MT, Ferini-Strambi L, Aridon P, Oldani A, Zucconi M, Casari G. Autosomal dominant restless legs syndrome maps on chromosome 14q. Brain 2003; 126: 1485-1492.

15. Chen S, Ondo WG, Rao S, Li L, Chen Q, Wang Q. Genomewide linkage scan identifies a novel susceptibility locus for restless legs syndrome on chromosome 9p. Am J Hum Genet 2004; 74: 876-885.

16. Pichler I, Marroni F, Volpato CB, Gusella JF, Klein C, Casari $G$, et al. Linkage analysis identifies a novel locus for restless legs syndrome on chromosome $2 \mathrm{q}$ in a South Tyrolean population isolate. Am J Hum Genet 2006; 79: 716-723.

17. Levchenko A, Provost S, Montplaisir JY, Xiong L, St-Onge $\mathrm{J}$, Thibodeau $\mathrm{P}$, et al. A novel autosomal dominant restless legs syndrome locus maps to chromosome 20p13. Neurology 2006; 67: 900-901. 